\title{
Strengthen the Process Management of Postgraduate Education on the Professional Degree
}

\author{
Da Yang ${ }^{1, a^{*}}$ \\ ${ }^{1}$ Jilin Agricultural University, Jilin, China \\ ayangnan1983116@163.com \\ *The corresponding author
}

Keywords: Process management; Postgraduate education; Professional degree.

\begin{abstract}
The postgraduate education of professional degree must implement process management. The implementation of process management on postgraduate education of professional degree need improve the rules and regulations and perfect information management system. The implementation of process management also need to help professional postgraduates master clear their value orientation, establish hand perfect the system of quality evaluation control.
\end{abstract}

\section{The Postgraduate Education of Professional Degree Need to Implement Process Management}

Process management is a kind of management theory which put forward by the target management. Target management emphasizes that management activities need to achieve the overall expectations. Process management advocates that management activities should refine to each process in the work of the nodes. Through the detailed microscopic process management, so as to improve enterprise's execution and achieve the goal of total quality management. Process management theory can be summarized as three points: the first is to emphasis on ordering management style, the second is to pay attention to prophase planning organization's activities, the third is to attach great importance to the organization in the process of monitoring and evaluation.

Professional degree is to meet the needs of certain social professions, aims to develop the strong professional ability and professional quality, creatively engage high-level talents in practical work. Vigorously develop the graduate education of full-time masters professional degree with Chinese characteristics that is the degree and postgraduate education initiative to adapt to the economic and social development of the urgent need of high-level talents. The ministry of education in 2009 does a good job of full-time masters degree graduate students cultivate several opinions which pointed out that full-time professional degree graduate training goal is to cultivate master a professional (or career) solid basic theory and wide in the field of professional knowledge, strong ability to solve problems, to undertake professional technical or management work, has the good professional quality of high-level talents. Professional fields including engineers, doctors, teachers, lawyers, accountants, etc. Professional degree and academic degree while at the same level, but the former closer with the professional integration, the latter is more emphasis on theory and research. Undergraduate course graduates of the full-time master's degree graduate student education is different from part-time professional degree graduate students, also differs from academic graduate student enrolled from recent college graduates.

The relationship between goal and process determines the value of the process management. In management activities, the management goal is the destination of process, it's the principle and flag of process specification and guidance. The realization of the goal depends on the scientific and reasonable corresponding process, the process is an important means, it is the premise and guarantee. Therefore, to truly realize the goal of cultivating the professional master should really implement process management, obtain from each concrete link. 
Adherence to process management is the inevitable choice of improving quality. The improvement of education quality of teaching is a gradual process, which need each link of practice system cooperation and close cooperation. Every step should be sure to put in place in the process, whether the establishment and perfection of teaching system, and the formulation and implementation of teaching plan, all need to check. The negligence or omission in each process details of is likely to hinder the overall teaching quality directly.

Implement process management is the only way to ensure healthy development of the professional degree education. Due to the lack of national supporting system, the traditional concept of "degree" effect deeply, the public in a short period of time what is difficult to agree with professional degree education. Low public recognition and support seriously hindered the healthy development of professional degree education. A good number of students are difficult to guarantee, part of the pilot on the guiding ideology of colleges and universities recruit professional master of pure as revenue channels. On the curriculum, to be weaken the professional characteristic of master, not according to the master's inherent law of professional courses, similar to the phenomenon of academic degree is relatively common. Lack of features, the quality directly led to the professional master degree in education function alienation, negative social impacts. So the implementation of process management, to strengthen the system construction has become a guarantee of professional degree education, maintain the good social image and promote its healthy development.

The graduate education of professional degree is still in exploring stage, there is no ready-made model. The management of graduate student that process management combined objective management .And the graduate student education in professional master's degree which strengthen the process management. Because professional master of management of occupational is strong, the students, admissions, training modes have flexibility and variability. It brings larger challenges to the management. The professional degree education of our country is still at the exploratory stage, therefore, only to strengthen the working process of the details of management, timely summary and improve how to ensure the quality of the cultivation of the professional master.

Part of the master of professional values have deviation which must correctly guide. Professional master has specific career orientation, the students are mostly back to the original position after graduation that have a certain closed or directional property. Compared with academic master, the occupational stress of professional master is relatively small, as a result, many students learning attitude is not correct and the purpose is not clear. This requires colleges and universities to strengthen the process management of professional master, to help they planning good personal learning goals and learning content, while correct their learning motivation.

Master of professional engineering have more loopholes in management. At present, the professional master's cultivation pattern can be roughly divided into three types: the first is off-job training which focus on learning in school, the rest of the time for decentralized on-the-job learning, the second is focus on cold, summer vacation time intensive study, the rest of the time autonomous decentralized learning, and the third is mixed cultivation way that is a variety of training modes coexist. It is not hard to see, the cultivation of one full-time years of concentrated study method for the optimal form, as well as specification for colleges and universities management provide many favorable conditions, and contribute to professional master degree studying, eliminate interference. However, due to some professional master's are part-time, and backbone for the unit, office units will be difficult to get a year of plenty time to fully off-job learning, there are many colleges and universities have not taken off-job training way of year, therefore, the master of professional engineering contradictions, cannot digest absorb knowledge and full time reading, learning is difficult to guarantee. In addition, students relatively scattered, also bring many problems to the 
teaching management, many students lack of sufficient effective communication with the teacher and the loopholes in management.

\section{How to Implement the Process Management about the Graduate Education of Professional Degree}

To establish and perfect rules and regulations that are the discipline of process management. Process management is an orderly circulation system. Among them, to establish and perfect rules and regulations is the primary part of process management. It is orderly legal basis of management process, as well as manager clear division of labor, according to legal guarantee. Relevant state administrative departments to keep pace with the times, strengthen propaganda, to improve the whole social recognition and support of professional master's degrees, thus for the further development to create a good social public opinion and psychological environment. It is a manager in the implementation of process management in the construction of the professional degree of specific performance. At the same time, they should be made to break through the institutional barriers, improve the system of form a complete set, more support from the policy. On the system to establish a professional master's degree and the related qualifications of cohesion, to arouse the students a strong desire to improve their own quality, enlarge high quality students. Not only such, school administrators to comprehensive research, implements the lawful, administering education according to law. At the same time, coordinate the relationship between the parties, regulate the behavior of the teachers and students, to overcome the obstacles in management, improve management efficiency.

Information management system is the technical support of process management. The agreement which with understanding is essential to the implementation of process management. All the teachers and students are the practitioners, process management and process management of beneficiaries. When all the teachers and students fully realize the importance of process management, clear all kinds of school education teaching standard and to carry out, natural get twice the result with half the effort. Due to dispersion of professional masters relatively concentrated study time is shorter, therefore, they should be completely reverse the traditional management system of colleges and universities in sealing ability of the limitations of paper documents, to set up a set of complete teaching management information systems, rules and regulations placed directly on the information platform, for teachers and students to read, expand propaganda. Through management system with clear responsibilities, rights in order to avoid repetition, reasonable use of teaching resources, and management thinking is deeply rooted in the hearts of the people. Information management system can regulate the school of teaching management of each process. In addition, through the information management, establish modern and efficient way to communicate with students in colleges and universities, development of multimedia teaching courseware, remote education advisor, accelerate the construction of network course full extension of classroom teaching.

Quality is the lifeline of graduate education. The graduate education quality of full-time professional degree should be geared to the needs of adapting to social development and improving their professional levels, the needs of increasing the competitiveness of employment, the value orientation of application guidance and professional potential. The postgraduate education of professional degree and academic degree talent training goal are different, lead to professional degree graduate education in the teaching idea, teaching requirements and the particularity of the dissertation. On the other hand, the full-time graduate and professional degree is given priority to with on-the-job work part-time professional degree graduate students, they are learning 
consciousness and learning target, depth of understanding of knowledge and true feelings, hope for learning effect is obvious differences.

Help students master clear their value orientation. In the process of management, some details of time and space hard to grasp directly, will inevitably lead to too much responsibility to do after off duty. Therefore, successful process management largely depends on that the students themselves clear positive learning motivation and good self-discipline consciousness. This requires professional students must possess a good process of management ability. Also, the lack of a part of self process management process manage mentis also not perfect. Students should clear their value orientation, namely be applied to satisfy the needs of the particular industry or professional practical work high-level specialized talents. At the same time, to cultivate students active must be within the target on the consciousness of their own direction, efforts to improve the self-awareness, the self-motivation, the self-discipline and self-regulation and the ability to self supervision and evaluation. In addition, we should also pay special attention to the important role of professional graduate student cadres. They are designated or elections, in the professional master has extensive demonstration and authority, they shall be responsible for daily management, professional master and as representative contact with universities, due to the personnel capable, facilitate coordination, can manage relative to release the inconvenience. They can give full play to the exemplary vanguard role in the management process and effective to increase the cohesion of group.

\section{Conclusion}

The quality improvement of graduate education is a long-term process. The career oriented goal and value orientation of full-time professional degree graduate education determines that it should comply with the general rules of graduate student education training, also has its special regularity.

\section{Reference}

[1] Nancy-Jane Lee. Professional doctorate supervision: Exploring student and supervisor experiences [J]. Nurse Education Today, 2009, 29: 641-648

[2] Denning Peter J. Professional Software Engineering Education [J]. Annals of Software Engineering, 1998, 6: 145-166 